\title{
FORMULATION AND EVALUATION OF TABLET PREPARED BY COAMORPHOUS SYSTEM CONTAINING ANTI-HYPERTENSIVE AND ANTI-HYPERLIPIDEMIC DRUG
}

\author{
SACHIN BASAVARAJ ADAHALLI", MANJULA TALLURI \\ Department of Pharmaceutics, PES College of Pharmacy, Bangalore 560050, Karnataka, India \\ Email: sachin.adahalli@gmail.com
}

Received: 17 May 2016 Revised and Accepted: 22 Jul 2016

\section{ABSTRACT}

Objective: Amlodipine besylate (AML) and Atorvastatin calcium (ATR) belong to biopharmaceutical classification system (BCS) class II (i.e. low solubility and high permeability) which leads to variable bioavailability. Hence, the aim of this study was to enhance the solubility of both drugs by utilizing the co-amorphous technique. This converted form and physical mixture of both drugs were utilized in the formulation of tablets.

Methods: The co-amorphous system was prepared by using rotary flash evaporator. Solubility study was carried out to investigate the dissolution advantage of prepared co-amorphous form. Total twelve formulations were formulated by keeping constant drugs concentrations utilizing direct compression technique among which F1 to F6 contains co-amorphous AML-ATR (Co-A AML-ATR) and F7 to F12 contains a physical mixture of AML and ATR as active pharmaceutical ingredient (APIs). Pre-compression and post-compression studies were carried out to all twelve formulations. Stability study was performed to the optimized formulations as per ICH guidelines.

Results: Mixture obtained after evaporation was found to become amorphous. FTIR study shows no evidence of intermolecular interactions between AML and ATR. The solubility of both AML and ATR were increased in almost one fold as compared to their respective crystalline counterparts. Pre-compression parameters of all twelve formulations blend fall under excellent to fair to flow properties. Post-compression parameters of all twelve formulations were within the specifications. But in vitro drug release of formulations F5, F6, F11, and F12 showed \% drug release as per IP. Stability study of optimized formulations was observed with, no significant difference in \% drug release.

Conclusion: The co-amorphous system can be prepared by utilizing rotary flash evaporator and the same was confirmed by XRPD and FTIR studies. The dissolution rate of the co-amorphous system was greater than that of the crystalline counterpart. Based on the results; F5 and F6 are considered as optimized formulations. Optimized formulations were stable during the stability study.

Keywords: Amlodipine besylate, Atorvastatin calcium, the Co-amorphous system of AML-ATR, Rotary flash evaporator, Direct compression, Sodium starch glycolate, Crospovidone, and Stability study

(C) 2016 The Authors. Published by Innovare Academic Sciences Pvt Ltd. This is an open access article under the CC BY license (http://creativecommons. org/licenses/by/4. 0/) DOI: http://dx.doi.org/10.22159/ijpps.2016.v8i9.12895

\section{INTRODUCTION}

Early trials on the treatment of hypertension based upon high doses of diuretics or beta blockers demonstrated a significant reduction in stroke but a less prominent decline in the incidence of coronary heart disease. This relative lack of coronary benefit may have been related to the adverse effect of these antihypertensive agents on plasma lipids since even small elevations in serum cholesterol may significantly increase coronary risk, particularly in patients with underlying hypertension. Drug-induced changes in lipid levels may be particularly important in hypertensive since up to 40 percent of untreated patients with primary hypertension (formerly called "essential" hypertension) already have lipid abnormalities, such as a high LDL-cholesterol and a low HDL-cholesterol.

Hence, hypertension frequently coexists with hyperlipidemia and both are considered to be major risk factors for developing cardiac disease ultimately resulting in adverse cardiac events. This clustering of risk factors is potentially due to a common mechanism. Further, patient compliance with the management of hypertension is generally better than patient compliance with hyperlipidemia. It would, therefore, be advantageous for patients with the intent of providing commercially viable multi-dose combinations in tablet dosage form to have a single therapy which treats both these conditions and minimizing tablet weight to assure patient acceptance $[1,2]$.

In this regard many combination treatments have come into the market namely, amlodipine besylate with atorvastatin calcium, telmisartan with atorvastatin, olmesartan with atorvastatin, simvastatin with aspirin with lisinopril with atenolol, atorvastatin calcium with metoprolol tartrate [3]. Among these available combinations, we opted combinational drug therapy as amlodipine besylate (AML) and atorvastatin calcium (ATR). This combination is bioequivalent to amlodipine and atorvastatin gave alone and does not modify the efficacy of either single agent, therapeutically shows a synergistic antioxidant effect on lipid peroxidation in human lowdensity lipoproteins and membrane vesicles enriched with polyunsaturated fatty acids, whereby these synergistic combinations are useful in treating subjects suffering from angina pectoris, atherosclerosis, combined hypertension and hyperlipidemia and those subjects presenting with symptoms of cardiac risk, including human. By utilizing this combination as an advantage on unconscious and unresponsive hypertensive patients thereby improving patient compliance, decreasing the cost of the treatment and number of pills $[4,5]$.

AML and ATR are one of the most frequently prescribed drug combinations in the world and oral route of choice for the drug administration due to its ease of administration, high patient compliance, cost-effectiveness, least sterility constraints and flexibility in the design of dosage form. But the major problem with both AML and ATR is 'low aqueous solubility'. The term 'low aqueous solubility' means that the drug has a solubility of less than about $10 \mathrm{mg} / \mathrm{ml}$, and preferably less than about $5 \mathrm{mg} / \mathrm{ml}$, in aqueous media at approximately physiological temperatures and $\mathrm{pH}$. The bioavailability of these drugs can be limited by poor dissolution of the drug into aqueous bodily fluids the following administration. This rate-limiting step may, therefore, be critical to rapidly attaining therapeutically effective amlodipine and atorvastatin drugs levels, inadequate and variable bioavailability and gastrointestinal mucosal toxicity [6-10]. A number of novel approaches for enhancing the low aqueous solubility of drugs have been attempted and continued to evolve over a period. Reduction in particle size (nano-drug delivery) and increased surface area, the use of alternative salt forms, 
solubilization of drug in co-solvents or micellar solutions, complexation with cyclodextrins or the use of lipid-based vehicles for the delivery of lipophilic drugs to name few. Among which coamorphous system also is an alternative and novel approaches for the enhancement of solubility. In these systems, a combination of two small molecules (drugs or excipients) is used instead of drugpolymer mixtures. These systems have been found to provide high stability and enhanced dissolution rates for the drugs. There are several publications in the area of amorphous binary systems like ritonavir with indomethacin, naproxen with cimetidine, simvastatin with glipizide, and atorvastatin with nicotinamide [11-13].

With this background, the present study was undertaken to develop a formulation containing co-amorphous forms of drugs AML and ATR useful for a population with the co-morbid condition of hypertension and hyperlipidemia.

\section{MATERIALS AND METHODS}

\section{Chemicals and reagents}

Amlodipine besylate and atorvastatin calcium are the gift samples from Dr. Reddy's Laboratories limited, Telangana (India). Methanol purchased from Sisco Research Laboratories Pvt. Ltd. Mumbai, India. Sodium starch glycolate (SSG), crospovidone (CP), microcrystalline cellulose, colloidal silicate and magnesium stearate were purchased from Sigma-Aldrich Corporation, Bengaluru, India. Potassium dihydrogen phosphate and potassium bromide (IR grade) were purchased from Merck, Mumbai, India. All other reagents were of analytical grade.

\section{Methods}

\section{Melting point}

The melting point of AML and ATR was determined by taking a small amount of both the drug in separate capillary tubes were closed at one end and placed in a melting point apparatus and the temperature at which drug melts was recorded. This was performed in triplicates and the average value was noted.

\section{Solubility study}

The solubility studies were performed in phosphate buffer $\mathrm{pH}$ 6.8, by adding excess amounts of AML, ATR, and co-amorphous system in each case to form saturated solution and keeping flasks on a rotary shaker with an agitation speed of $200 \mathrm{rpm}$ and temperature controlling system of $\pm 0.1{ }^{\circ} \mathrm{C}$ for $24 \mathrm{~h}$. After $24 \mathrm{~h}$, solutions were filtered through $0.45 \mu \mathrm{m}$ filters and diluted with phosphate buffer $\mathrm{pH} 6.8$ and analyzed using UV spectrophotometer (Shimadzu UV-1800, Japan) at $365 \mathrm{~nm}$ and $241 \mathrm{~nm}$ for amlodipine besylate and atorvastatin calcium respectively, which are the absorption maxima's determined earlier and drug concentrations were calculated.

\section{FT-IR Study $[14,15]$}

This was carried out to find out the compatibility between the physical mixture of AML and ATR, prepared co-A AML-ATR and
AML-ATR mixtures with polymers such as sodium starch glycolate, crospovidone, microcrystalline cellulose, colloidal silicate, and magnesium stearate. $10 \mathrm{mg}$ of the sample and $400 \mathrm{mg}$ of $\mathrm{KBr}$ were taken in a mortar and triturated. A small amount of the triturated sample was taken into a pellet maker and was compressed at a 10 $\mathrm{kg} / \mathrm{cm}^{2}$ hydraulic press. The pellet was kept onto the sample holder and scanned from $4000 \mathrm{~cm}^{-1}$ to $600 \mathrm{~cm}^{-1}$ in FT-IR spectrophotometer (Shimadzu FTIR-8700). The spectra obtained were compared and interpreted for the functional group peaks.

\section{Preparation of amorphous precipitate of AML-ATR binary system [11, 13]}

The co-amorphous system of AML and ATR were prepared by solvent evaporation technique using methanol as a solvent. A total of $1500 \mathrm{mg}$ in $1000 \mathrm{mg}$ of atorvastatin calcium and $500 \mathrm{mg}$ of amlodipine besylate were mixed homogeneously and then dissolved in $20 \mathrm{ml}$ methanol. The solvent was evaporated under reduced pressure at $40{ }^{\circ} \mathrm{C}$. The residual solvent left after evaporation was then removed completely by placing the sample under vacuum for 2 $\mathrm{d}$ inside desiccator containing $\mathrm{CaCO}_{3}$. The precipitates were stored in a desiccator until its use in the experiment.

\section{X-ray powder diffractometry (XRPD) [16]}

X-ray powder diffraction patterns were obtained using Rigaku miniflex 600 X-ray diffractometer (Rigaku Co., Tokyo, Japan) for pure AML, ATR and co-amorphous form of AML-ATR (co-A AMLATR). The instrument was operated at 600 watts (X-ray tube), with a fixed tube current of $15 \mathrm{~mA}$ and a voltage of $40 \mathrm{kV}$. The diffracted Xray beam was monochromated by a graphite monochromator and a standard scintillation counter was used as the detector. Diffraction intensities were measured by fixed time step scanning method in the range of $0-50^{\circ}(2 \theta)$.

\section{Preparation of tablets containing physical mixture of ATR and AML and co-A AML-ATR by direct compression}

All the solid raw materials were dispensed, packed in an individual in clean poly bags and labeled. Separately weighted quantities as given in table 1 of formulation F1 to F6 containing of co-A AML-ATR, sodium starch glycolate, crospovidone, and microcrystalline cellulose sifted through \#30 mesh and colloidal silicate and magnesium stearate through \#60 mesh. All the above-sifted materials are collected individually into a double-lined polyethylene bag. The co-amorphous system of AML-ATR, crospovidone XL, sodium starch glycolate, and microcrystalline cellulose was mixed in a mortar and pestle for $10 \mathrm{~min}$. To the premixed blend, colloidal silicate was added and thoroughly mixed for $15 \mathrm{~min}$. Lubricate the above blend with magnesium stearate and hand blend (mix) for 5 min. The tablets were prepared using $8 \mathrm{~mm}$ Flat Faced Bevel Edged (FFBE) punches. The tablets were compressed by maintaining a constant hardness $7 \pm 0.5 \mathrm{~kg} / \mathrm{cm}^{2}$.

For the formulation F7 to F12 of the tablets containing a physical mixture of AML and ATR, similar steps were followed and quantities are given in table 2.

Table 1: List of materials and quantities for formulations F1 to F6

\begin{tabular}{|c|c|c|c|c|c|c|}
\hline \multirow[t]{2}{*}{ Name of the ingredients } & \multicolumn{6}{|c|}{ Quantity/Unit dose (mg) } \\
\hline & F1 & F2 & F3 & F4 & F5 & F6 \\
\hline Co-A AML-ATR (5 mg of AML and $10 \mathrm{mg}$ of ATR) & 15 & 15 & 15 & 15 & 15 & 15 \\
\hline Sodium starch glycolate & 5 & - & 10 & - & 15 & - \\
\hline Crospovidone & - & 5 & - & 10 & - & 15 \\
\hline Microcrystalline cellulose & 175 & 175 & 170 & 170 & 165 & 165 \\
\hline Colloidal silicate & 2 & 2 & 2 & 2 & 2 & 2 \\
\hline Magnesium stearate & 3 & 3 & 3 & 3 & 3 & 3 \\
\hline Weight of the tablet (mg) & 200 & 200 & 200 & 200 & 200 & 200 \\
\hline
\end{tabular}

\section{Pre-compression parameters [17-19]}

Pre-compression parameters like Bulk density (Db), Tapped density (Dt), Compressibility index (Carr's Index), Hausner's ratio and Angle of repose were performed to all formulation blends.
Post-compression parameters [14, 20-25]

\section{Thickness}

The thickness and diameter of the tablet were measured using Vernier calipers. It is measured in $\mathrm{mm}$. 
Table 2: List of materials and quantities for formulations F7 to F12

\begin{tabular}{|c|c|c|c|c|c|c|}
\hline \multirow[t]{2}{*}{ Name of the ingredients } & \multicolumn{6}{|c|}{ Quantity/Unit dose (mg) } \\
\hline & F7 & F8 & F9 & F10 & F11 & F12 \\
\hline AML & 5 & 5 & 5 & 5 & 5 & 5 \\
\hline ATR & 10 & 10 & 10 & 10 & 10 & 10 \\
\hline Sodium starch glycolate & 5 & - & 10 & - & 15 & - \\
\hline Croospovidone & - & 5 & - & 10 & - & 15 \\
\hline Microcrystalline Cellulose & 175 & 175 & 170 & 170 & 165 & 165 \\
\hline Colloidal silicate & 2 & 2 & 2 & 2 & 2 & 2 \\
\hline Magnesium Stearate & 3 & 3 & 3 & 3 & 3 & 3 \\
\hline Weight of the tablet (mg) & 200 & 200 & 200 & 200 & 200 & 200 \\
\hline
\end{tabular}

\section{Weight variation test}

20 tablets were selected at random from the lot, weighed individually and the average weight was determined. The percent deviation of each tablets weight against the average weight was calculated. The test requirements are meets, if not more than two of the individual weights deviate from the average weight by not more than existing $7.5 \%$.

\section{Hardness}

The prepared tablets were subjected to hardness test. It was carried out by using hardness tester and expressed in $\mathrm{kg} / \mathrm{cm}^{2}$.

\section{Friability (F)}

The friability was determined using Roche friabilator and expressed in percentage (\%). 10 tablets from each batch were weighed separately $\left(\mathrm{W}_{\text {initial }}\right)$ and placed in the friabilator, which was then operated for 100 revolutions at $25 \mathrm{rpm}$. The tablets were weighed $\left(\mathrm{W}_{\text {final }}\right)$ and the percentage friability was calculated for each batch by using the following formula.

$$
\% \text { Friability }=\frac{\text { Initial weight }- \text { Final kweight }}{\text { Initial weight }} \times 100
$$

\section{Uniformity of drug content}

The prepared tablets were tested for their drug content. 20 tablets of each formulation were finely powdered; weight equivalent to $5 \mathrm{mg}$ of AMD and $10 \mathrm{mg}$ of ATR and the same was completely extracted with methanol by sonication for $10 \mathrm{~min}$ in a $100 \mathrm{ml}$ volumetric flask and this solution was filtered through Whatman no.1 filter paper. The residue was washed with $10 \mathrm{ml}$ methanol three times and volume made up to $100 \mathrm{ml}$ with methanol. The solution obtained was diluted with the Methanol so as to obtain a concentration in the range of linearity previously determined. The concentration of both AMD and ATR were determined by measuring the absorbance of the sample at $365 \mathrm{~nm}$ and $241 \mathrm{~nm}$ respectively.

\section{Disintegration time}

The in vitro disintegration time of a tablet was determined using disintegration test apparatus as per I. P. specifications. One tablet is placed in each of the 6 tubes of the basket. The experiment was done by using Phosphate buffer $\mathrm{pH} 6.8$ maintained at $37 \pm 2{ }^{\circ} \mathrm{C}$ as the immersion liquid. Assembly raised and lowered between 30 cycles. The time taken for the tablet to complete disintegration with no palpable mass remaining in the apparatus was measured was recorded in $\mathrm{s}$

\section{Water absorption ratio}

A piece of tissue paper folded twice was placed in a small Petri dish Containing $6 \mathrm{ml}$ of water. A tablet was put on the tissue paper and allowed to completely wet. The wetted tablet was then weighted. Water absorption ratio, $\mathrm{R}$ was determined using following equation.

$$
\mathrm{R}=\frac{\mathrm{Wa}-\mathrm{Wb}}{\mathrm{Wa}} \times 100
$$

Where,

Wa $=$ Weight of tablet after water absorption

$\mathrm{Wb}=$ Weight of tablet before water absorption

\section{Wetting time}

In wetting time a piece of tissue paper folded twice was placed in a small petri dish (internal diameter $=6.5 \mathrm{~cm}$ ) containing $10 \mathrm{ml}$ of $5 \%$ amaranth solution, a tablet was placed on the paper, and the time for complete wetting was measured. Three trails for each batch were performed and the standard deviation was also determined.

\section{In vitro drug release}

The in vitro dissolution studies were carried out for the formulations using USP apparatus type II (Paddle type). The dissolution medium used was $900 \mathrm{ml}$ of phosphate buffer of $\mathrm{pH} 6.8$ for $30 \mathrm{~min}$. The temperature was maintained at $37{ }^{\circ} \mathrm{C} \pm 0.5{ }^{\circ} \mathrm{C}$ and the stirring rate was $50 \mathrm{rpm} .5 \mathrm{ml}$ of samples were withdrawn at intervals of $5 \mathrm{~min}$ up to $30^{\text {th }} \mathrm{min}$; the same volume was replaced with freshly prepared pH 6.8 phosphate buffer. The samples were measured by UV Spectrophotometer at $365 \mathrm{~nm}$ and $241 \mathrm{~nm}$ against blank for AML and ATR respectively. The release studies were conducted in triplicate and the mean values were plotted versus time.

\section{Stability study [26]}

The selected formulations were packed in a suitable container, which mimics the final packing. They were then stored at $25{ }^{\circ} \mathrm{C} \pm 2$ ${ }^{\circ} \mathrm{C} / 60 \% \pm 5 \% \mathrm{RH}$ and $40{ }^{\circ} \mathrm{C} \pm 2{ }^{\circ} \mathrm{C} / 75 \% \pm 5 \% \mathrm{RH}$ and kept for three months and evaluated for their hardness, drug content, and drug release at specific intervals of time as per ICH Guidelines.

\section{Statistical analysis}

One way ANOVA followed by Tykey method opted as a statistical analysis of obtained in vitro release data. A probability value of $p<0.05$ was considered as statistically significant.

\section{RESULTS AND DISCUSSION}

\section{Melting point}

Melting point analysis is one of the quality control tests. The melting point of pure AML and ATR were given in below table 3. By comparing reported melting point with an actual melting point which are in the range of IP specification and have sharp melting point hence, both the drugs which are of genuine and crystalline in nature.

Table 3: Melting point of AML and ATR

\begin{tabular}{lll}
\hline Name of the drug & Melting point & \\
\cline { 2 - 3 } & Actual & Reported* \\
\hline AML & $178-179^{\circ} \mathrm{C}$ & $178.33^{\circ} \mathrm{C} \pm 0.3055$ \\
ATR & $159.2-160.7^{\circ} \mathrm{C}$ & $160.33^{\circ} \mathrm{C} \pm 0.1155$ \\
\hline
\end{tabular}

${ }^{*}$ mean \pm SD $(\mathrm{n}=3)$ 


\section{Solubility studies}

The solubility of pure drugs and prepared co-amorphous system were showed in the graphical representation in fig. 1 and 2. The saturation solubilities of crystalline AML and ATR in phosphate buffer $\left(\mathrm{pH} 6.8\right.$ at $37{ }^{\circ} \mathrm{C}$ ) were $357.61 \mu \mathrm{g} / \mathrm{ml}$ and $100.14 \mu \mathrm{g} / \mathrm{ml}$, respectively. A statistically significant enhancement, i.e., almost one fold in the saturation solubilities of the individual components as compared to their crystalline counterparts were reported in the amorphous binary system these findings are similar as reported by A Shayanfar et al., 2013 and S. J. Dengale et al., 2014.

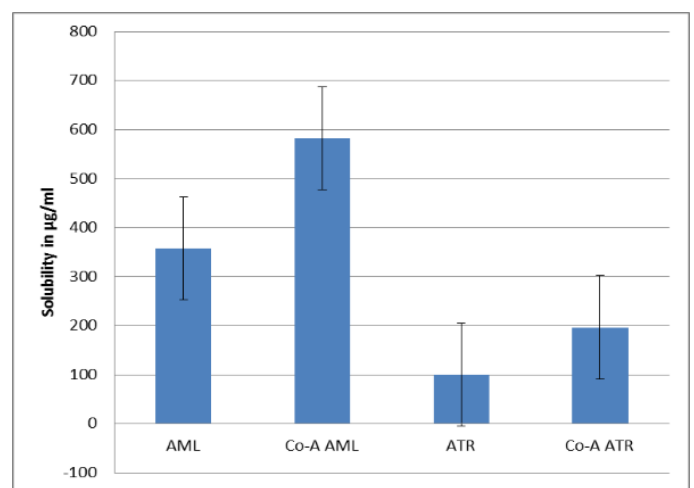

Fig. 1: Solubility representation in column chart of both AML and ATR in crystalline and co-amorphous form

\section{Drug-excipients compatibility studies}

FTIR spectroscopic studies were showed in table 4 and fig. 2, 3, 4, 5,6 , and 7. FTIR measurements were carried out to pure AML, ATR, a physical mixture of ATR-AML and with formulation blend and co-A AML-ATR and with formulation blend to in order to find out the interactions. AML showed strong peaks at 3297, 3158$2982,1676,1614-1493,1207,1095,995$, and $755-730 \mathrm{~cm}^{-1}$ which attribute $\mathrm{N}-\mathrm{H}$ stretching, $\mathrm{C}-\mathrm{H}$ stretching, $\mathrm{C}=\mathrm{O}$ stretching, aromatic $\mathrm{C}=\mathrm{C}$ stretching, $\mathrm{C}-\mathrm{O}$ stretching and $\mathrm{S}=\mathrm{O}$ stretching, $\mathrm{C}-\mathrm{O}-\mathrm{C}$ stretching, $\mathrm{C}-\mathrm{Cl}$ stretching, and aromatic $\mathrm{C}-\mathrm{H}$ bending respectively. Whereas for ATR at 3381, 2992-2900, 3670, 3055, 1662, 1595$1531,1157,1213,1224$ and $843-753 \mathrm{~cm}^{-1}$ for N-H stretching, C-H stretching, free $\mathrm{O}-\mathrm{H}$ stretching, $\mathrm{O}-\mathrm{H}$ stretching, $\mathrm{C}=\mathrm{O}$ stretching, aromatic $\mathrm{C}=\mathrm{C}$ stretching, $\mathrm{C}-\mathrm{N}$ stretching, C-O stretching, C-F stretching, and aromatic $\mathrm{C}-\mathrm{H}$ bending.

In order to detect the interaction between the two drugs, the individual spectrum of each drug was compared with the spectrums that of a physical mixture of AML-ATR, co-A AML-ATR separately and with formulation blend. The results of FTIR showed that the samples comply with FTIR spectrum given in the BP. It also concludes that there are no molecular interactions in drugs and with formulation blend and in co-A ATR-AML and with its formulation bled. In co-amorphous form, there is a decrease in intensities of all the peaks, broadening and slight shifts (i.e. minor hypsochromic) are observed for $\mathrm{N}-\mathrm{H}$ and $\mathrm{C}-\mathrm{H}$ functional groups, which is due to the hydrogen bonding between both the drugs due to the amorphous convertion. Hence, all the reports conclude that we can proceed with the formulation of tablet.

Table 4: Compatibility study of drugs with formulation blend

\begin{tabular}{|c|c|c|c|c|c|}
\hline \multirow[t]{2}{*}{ Drug/Formulation blend } & \multirow[t]{2}{*}{ Drug/formulation blend ratio } & \multirow[t]{2}{*}{ Physical description initial } & \multicolumn{3}{|c|}{$40{ }^{\circ} \mathrm{C} \pm 2{ }^{\circ} \mathrm{C} / 75 \% \pm 5 \% \mathrm{RH}$} \\
\hline & & & $1^{\text {st }}$ weak & $2^{\text {nd }}$ weak & $4^{\text {th }}$ weak \\
\hline Amlodipine besylate & - & White crystalline powder & $*$ & * & $*$ \\
\hline Atorvastatin calcium & - & White crystalline powder & $*$ & $*$ & * \\
\hline AML: ATR & 1: 1 & White crystalline powder & $*$ & $*$ & * \\
\hline AML: ATR: Blend & 1: $1: 1$ & White crystalline powder & $*$ & $*$ & * \\
\hline Co-A ATR-AML & - & White crystalline powder & * & * & $*$ \\
\hline Co-A ATR-AML: Blend & $1: 1$ & White crystalline powder & $*$ & $*$ & $*$ \\
\hline
\end{tabular}

*No incompatibility problem

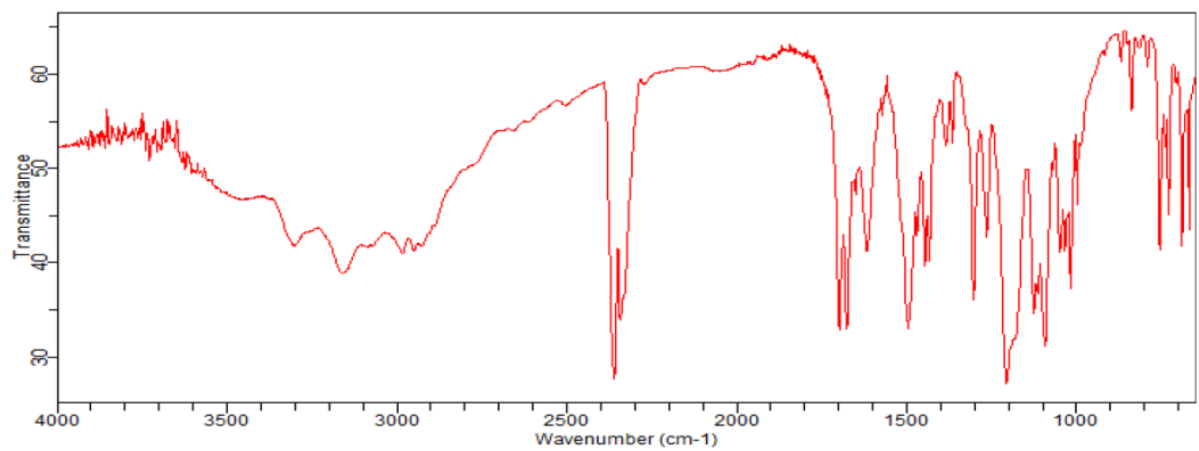

Fig. 2: FTIR spectra of AML

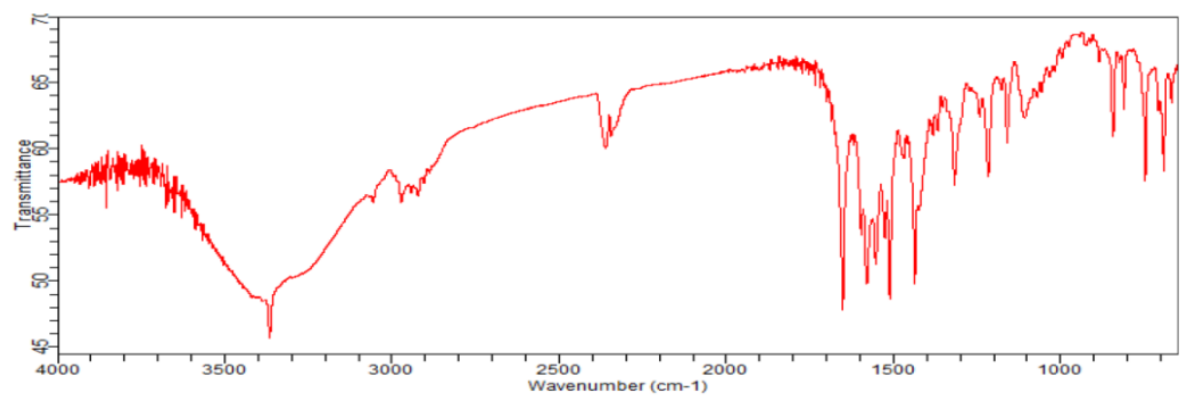

Fig. 3: FTIR spectra of ATR 


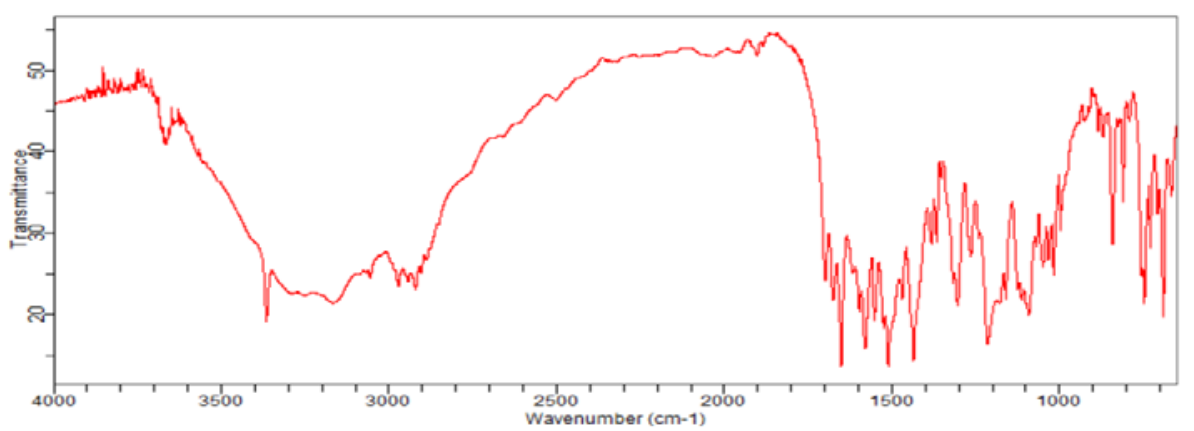

Fig. 4: FTIR spectra of physical mixture of AML and ATR

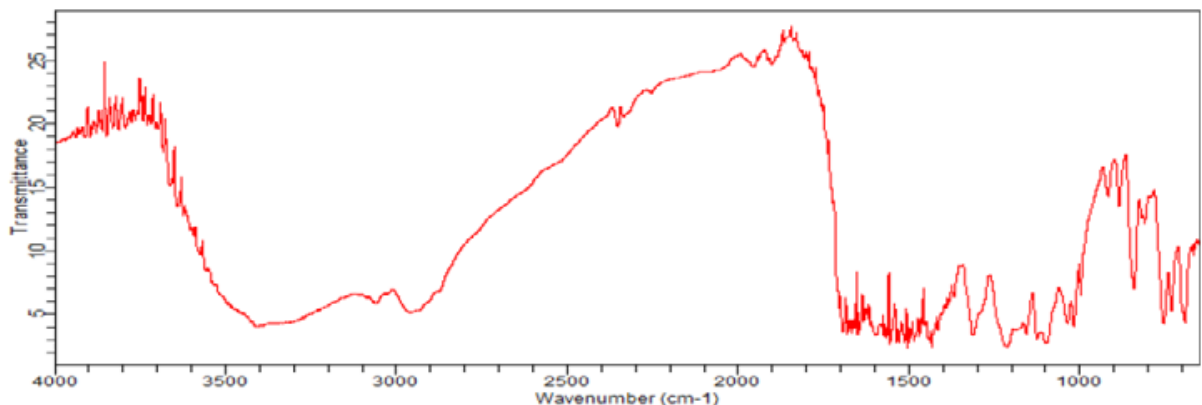

Fig. 5: FTIR spectra of co-A AML-ATR

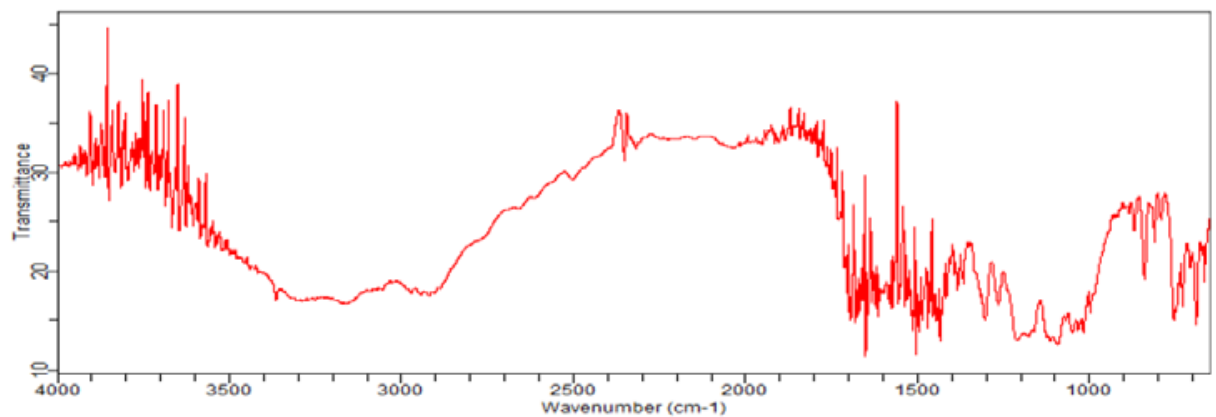

Fig. 6: FTIR spectra of physical mixture AML-ATR with formulation blend

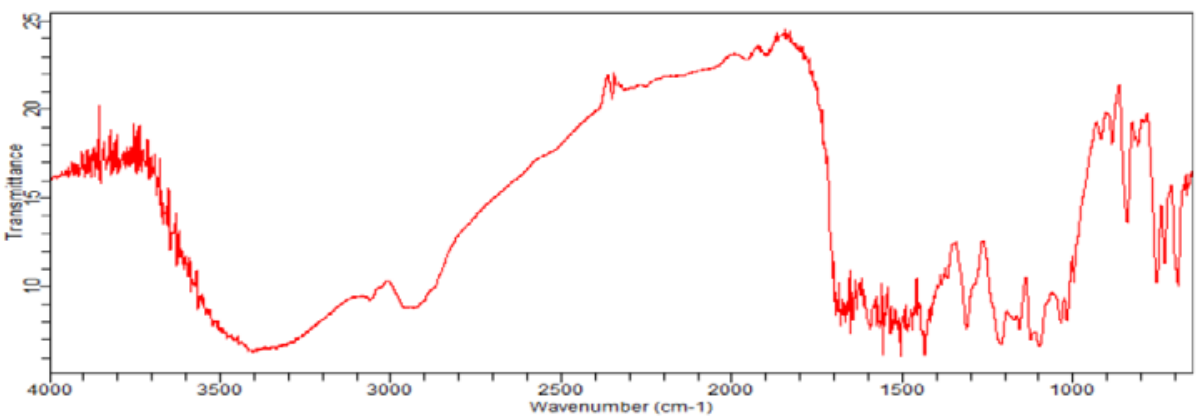

Fig. 7: FTIR spectra of co-A AML-ATR with formulation blend

\section{X-ray powder diffractometry (XRPD)}

To characterize the presence of amorphous nature, XRPD is considered as a gold standard method. XRPD does not detect the presence of amorphous form per say but instead detects the absence of crystallinity in the samples. The absence of crystallinity can be confirmed by spotting the halo pattern in the diffractogram. Fig. 8, 9, and 10, shows the XRPD patterns of crystalline AML, crystalline ATR and precipitated binary amorphous mixture co-A of AML-ATR respectively. Crystalline AML and ATR samples show a number of peaks in diffractogram, which confirms the crystalline nature of the individual drug. For the precipitated amorphous samples, the XRPD patterns show the typical halo (absence of crystalline peaks) suggesting amorphousness. 


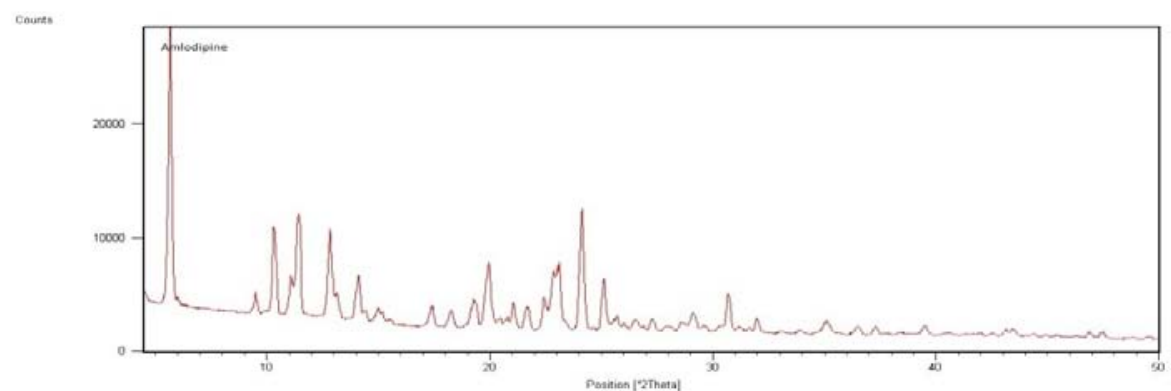

Fig. 8: X-ray powder diffractometer of AML

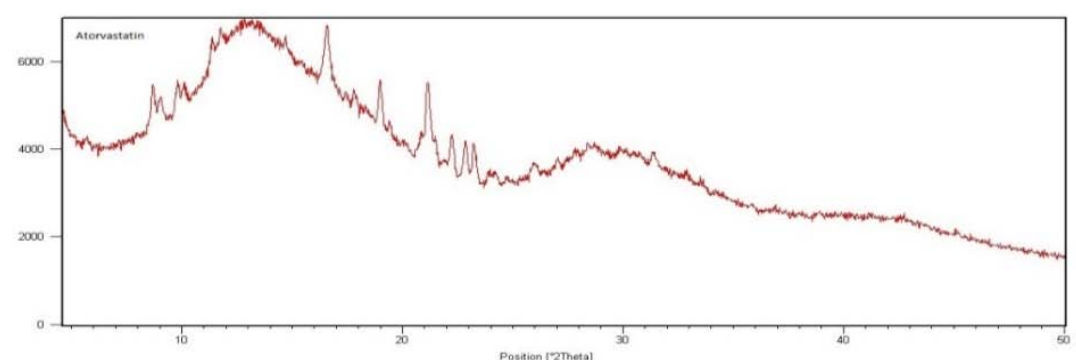

Fig. 9: X-ray powder diffractometer of ATR

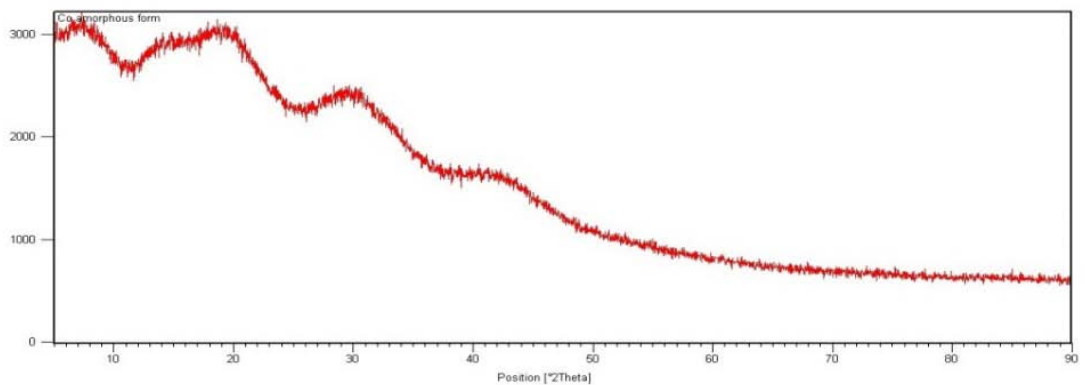

Fig. 10: X-ray powder diffractometer of co-amorphous AML-ATR

\section{Evaluation of pre-compression parameters of formulation blend}

Pre-compression parameters were performed in order evaluate the power flow properties like bulk density, tapped density, hausner's ratio, carr's index and angle of repose (table 5). Bulk density and tapped density of formulation blend F1 to F12 was performed and was found to vary from $0.276 \mathrm{gm} / \mathrm{cm}^{3}$ to $0.3184 \mathrm{gm} / \mathrm{cm}^{3}$ and 0.3 $\mathrm{gm} / \mathrm{cm}^{3}$ to $0.366 \mathrm{gm} / \mathrm{cm}^{3}$ respectively. Formulation blend of $\mathrm{F} 1$ to F12 was introduced to hausner's ratio analysis. The values are ranges from 1.04 to 1.24 which falls under excellent, good and fair to flow properties as per the specifications. The results of carr's index or compressibility index (\%) for the formulation blend F1 to F12 ranged from $4.638 \%$ to $24.59 \%$ that indicated excellent, good, fair, and passable flow properties.

The data obtained from the angle of repose for all the formulations were found to be in the ranges from $25.10 \pm 0.9271^{\circ}$ to $28.17 \pm 0.3383^{\circ}$. By looking at the ranges of pre-compression parameters, all the formulations F1 to F12 had excellent to pair to flow properties. The results of pre-formulation parameters of all formulations were in the acceptable range as per the specifications $[6,7,23]$. Hence, we were preceded by further studies.

Table 5: Evaluation of pre-compression parameters of formulation F1-F12

\begin{tabular}{|c|c|c|c|c|c|}
\hline Formulations & Bulk density* (gm/cc) & Tapped density* (gm/cc) & Hausner's ratio* & $\begin{array}{l}\text { Compressability } \\
\text { Index* }(\%)\end{array}$ & $\begin{array}{l}\text { Angle of repose* } \\
\Theta\end{array}$ \\
\hline F1 & $0.29 \pm 0.324$ & $0.3 \pm 0.623$ & $1.04 \pm 0.152$ & $13.14 \pm 0.047$ & $25.10 \pm 0.927$ \\
\hline $\mathrm{F} 2$ & $0.3 \pm 0.214$ & $0.31 \pm 0.236$ & $1.05 \pm 0.702$ & $5.4 \pm 0.154$ & $26.60 \pm 0.34$ \\
\hline F3 & $0.3 \pm 0.352$ & $0.32 \pm 0.321$ & $1.08 \pm 0.321$ & $6.94 \pm 0.137$ & $25.69 \pm 0.891$ \\
\hline $\mathrm{F} 4$ & $0.3 \pm 0.132$ & $0.32 \pm 0.184$ & $1.07 \pm 0.435$ & $6.93 \pm 0.29$ & $26.43 \pm 0.407$ \\
\hline F5 & $0.29 \pm 0.562$ & $0.31 \pm 0.126$ & $1.04 \pm 0.624$ & $4.64 \pm 0.186$ & $28.17 \pm 0.338$ \\
\hline F6 & $0.32 \pm 0.142$ & $0.34 \pm 0.161$ & $1.08 \pm 0.2$ & $7.49 \pm 0.347$ & $25.76 \pm 0.576$ \\
\hline F7 & $0.27 \pm 0.823$ & $0.31 \pm 0.726$ & $1.15 \pm 0.55$ & $13.14 \pm 0.42$ & $26.22 \pm 0.695$ \\
\hline F8 & $0.3 \pm 0.322$ & $0.34 \pm 0.425$ & $1.17 \pm 0.115$ & $13.75 \pm 0.25$ & $26.53 \pm 0.223$ \\
\hline F9 & $0.3 \pm 0.164$ & $0.34 \pm 0.132$ & $1.16 \pm 0.416$ & $15.25 \pm 0.132$ & $27.70 \pm 0.48$ \\
\hline F10 & $0.3 \pm 0.527$ & $0.37 \pm 0.121$ & $1.10 \pm 0.802$ & $24.59 \pm 0.292$ & $27.54 \pm 0.388$ \\
\hline F11 & $0.3 \pm 0.211$ & $0.36 \pm 0.636$ & $1.19 \pm 0.655$ & $16.01 \pm 0.454$ & $26.17 \pm 0.083$ \\
\hline F12 & $0.29 \pm 0.623$ & $3.65 \pm 0.493$ & $1.24 \pm 0.702$ & $19.64 \pm 0.385$ & $25.59 \pm 0.652$ \\
\hline
\end{tabular}

*mean \pm SD $(n=3)$ 


\section{Evaluation of post-compression parameters}

Formulations F1 to F12 continued for the evaluation of postcompression parameters like thickness, hardness, friability and weight variation. Results were ranges from $2.6 \pm 0.01$ to $2.784 \pm 0.02$, $5.42 \pm 0.12$ to $6.82 \pm 0.16 \mathrm{~kg} / \mathrm{cm}^{2}, 0.10 \%$ to $0.15 \%$ and $+1.19 \%$ to+2.66 \% and-1.039 \% to-2.3174\% (table 6, 7, 8 and 9) respectively. Uniformity of drug content in the each tablet plays a very important role, if low or high drug concentration; it leads to subtherapeutic and toxic levels respectively.

Hence in order to confirm the drug concentrations in each tablet; drug content uniformity test was performed, and results ranged from $96.83 \pm 0.8 \%$ to $103.9 \pm 0.5 \%$ for AML and $98.39 \pm 0.46 \%$ to $104.5 \pm 0.6 \%$ for ATR (given in table 6, 7 and 8 ). Hence, these results prove that both drugs are within the limits as per the IP.

Table 6: Evaluation of post-compression parameters of formulation F1-F12

\begin{tabular}{|c|c|c|c|c|c|}
\hline \multirow{2}{*}{$\begin{array}{l}\text { Tests } \\
\text { Formulations }\end{array}$} & \multirow{2}{*}{$\begin{array}{l}\text { Thickness* } \\
\text { in (mm) }\end{array}$} & \multirow{2}{*}{$\begin{array}{l}\text { Hardness* } \\
\text { in }\left(\mathrm{kg} / \mathrm{cm}^{2}\right)\end{array}$} & \multirow{2}{*}{$\begin{array}{l}\text { Friability* } \\
\text { in (\%) }\end{array}$} & \multicolumn{2}{|l|}{ Assay* } \\
\hline & & & & Amlodipine (\%) & Atorvastatin (\%) \\
\hline F1 & $2.7 \pm 0.01$ & $5.64 \pm 0.13$ & $0.13 \pm 0.02$ & $101.45 \pm 0.3$ & $98.93 \pm 0.7$ \\
\hline $\mathrm{F} 2$ & $2.6 \pm 0.01$ & $5.8 \pm 0.14$ & $0.11 \pm 0.01$ & $103.9 \pm 0.5$ & $99.60 \pm 0.5$ \\
\hline F3 & $2.7 \pm 0.01$ & $6.42 \pm 0.15$ & $0.14 \pm 0.01$ & $103.4 \pm 0.5$ & $99.73 \pm 0.3$ \\
\hline F4 & $2.7 \pm 0.01$ & $5.42 \pm 0.15$ & $0.11 \pm 0.01$ & $100.86 \pm 0.5$ & $102.55 \pm 0.6$ \\
\hline F5 & $2.8 \pm 0.01$ & $6.82 \pm 0.16$ & $0.15 \pm 0.01$ & $102.24 \pm 0.7$ & $104.5 \pm 0.6$ \\
\hline F6 & $2.8 \pm 0.02$ & $5.53 \pm 0.15$ & $0.12 \pm 0.02$ & $99.01 \pm 0.26$ & $102.2 \pm 0.45$ \\
\hline F7 & $2.7 \pm 0.01$ & $5.97 \pm 0.17$ & $0.10 \pm 0.01$ & $96.83 \pm 0.8$ & $103.03 \pm 0.4$ \\
\hline F8 & $2.8 \pm 0.01$ & $5.55 \pm 0.23$ & $0.13 \pm 0.02$ & $103.13 \pm 0.7$ & $101.1 \pm 0.4$ \\
\hline F9 & $2.8 \pm 0.01$ & $5.95 \pm 0.13$ & $0.11 \pm 0.02$ & $100.2 \pm 0.53$ & $98.39 \pm 0.46$ \\
\hline F10 & $2.8 \pm 0.01$ & $5.62 \pm 0.21$ & $0.12 \pm 0.01$ & $100.9 \pm 0.6$ & $100.83 \pm 0.7$ \\
\hline F11 & $2.8 \pm 0.01$ & $5.93 \pm 0.15$ & $0.10 \pm 0.01$ & $100.8 \pm 0.56$ & $99.67 \pm 0.74$ \\
\hline F12 & $2.7 \pm 0.01$ & $5.42 \pm 0.12$ & $0.12 \pm 0.01$ & $100.66 \pm 0.9$ & $101.17 \pm 0.8$ \\
\hline
\end{tabular}

${ }^{*}$ mean \pm SD $(n=3)$

Table 7: Weight variation of formulations (F1-F12)

\begin{tabular}{llll}
\hline Formulation & Average weight in mg & Positive deviation (\%) & Negative deviation (\%) \\
\hline F1 & 200.45 & +2.2698 & -1.22 \\
F2 & 201.65 & +1.66 & -2.3059 \\
F3 & 201.6 & +1.19 & -1.289 \\
F4 & 200.65 & +2.66 & -2.3174 \\
F5 & 200.4 & +1.796 & -1.696 \\
F6 & 201.6 & +1.686 & -1.2896 \\
F7 & 202.1 & +1.4349 & -1.039 \\
F8 & 201.15 & +1.91 & -1.5659 \\
F9 & 201.35 & +2.3 & -1.66 \\
F10 & 201.55 & +1.2155 & -1.76 \\
F11 & 201.4 & +1.787 & -2.184 \\
F12 & 200.8 & +2.589 & -2.39 \\
\hline
\end{tabular}

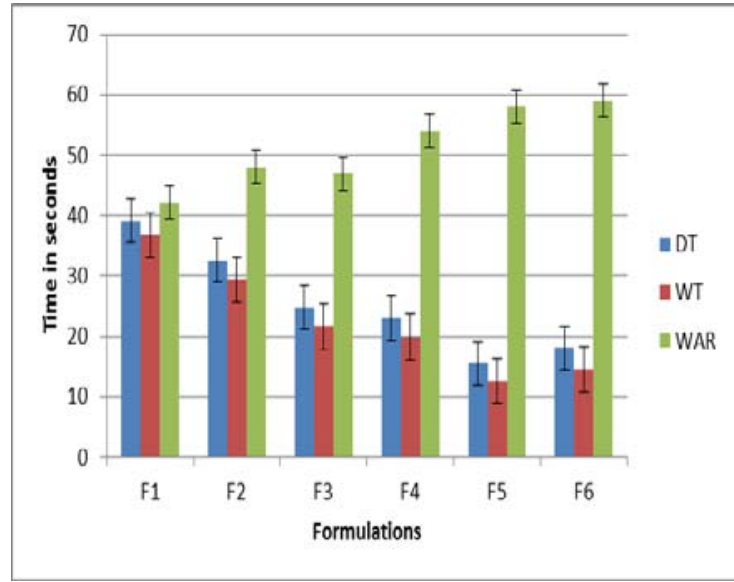

Fig. 11: Evaluations for disintegration time, wetting time, and water absorption ratio representation in column chart from formulations F1-F6

Evaluations for disintegration time, wetting time, and water absorption ratio

Average disintegration times of formulations F1 to F12 ranges from $15.53 \pm 0.5507$ to $39.16 \pm 0.2886 \mathrm{sec}$ and it was observed the decrease in disintegration time with an increase in concentrations of superdisintegrants [i.e. sodium starch glycolate (SSG) and crospovidone] hence, disintegration time is inversely proportional to superdisintegrant concentrations.

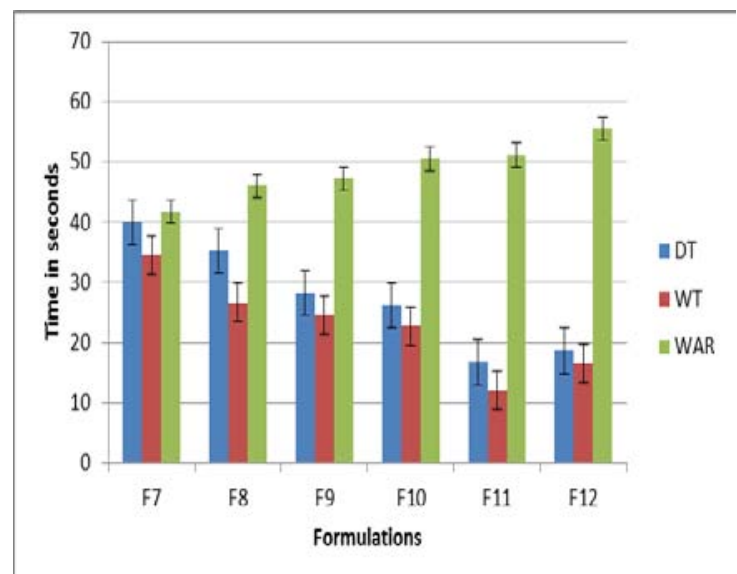

Fig. 12: Evaluations for disintegration time, wetting time, and water absorption ratio representation in column chart from formulations F7-F12 
The formulation F2, F4, F8, and F10 containing crospovidone as a super-disintegrant has lesser disintegration time compared to the SSG containing formulation F1, F3, F7, and F9. But in the formulations, F5, F6, F11 and F12 visa-verse effects has been observed with respect to SSG and crospovidone. In wetting time, similar effects have been observed as seen in the disintegration time. And it also observed that, wetting time of all the formulations is lesser than that of the disintegration time and which is ranges from $12.06 \pm 0.208$ to $36.73 \pm 0.3055 \mathrm{sec}$. In water absorption ratio, an increase in concentrations of super-disintegrants also increases the water absorption ratio (i.e. directly proportional) and which is range from $41.7 \pm 0.8885 \%$ to $59.03 \pm 0.2516 \%$. The results are in the specified limits as per IP and are given in fig. 11 and 12

\section{In vitro dissolution studies}

In vitro drug release of both AML and ATR from the formulation F1 to $\mathrm{F} 6$ were increases gradually due to the amorphous nature and effect of super-disintegrants and at $30^{\text {th }}$ min $\%$ cumulative drug release (CDR) of F1-67.27\% (AML) and 68.06\% (ATR), F2-71.96\% (AML) and 76\% (ATR), F3-76.16\% (AML) and 80\% (ATR), F478.23\% (AML) and 82.03\% (ATR), F5-101.7\% (AML) and $103.9 \%$ (ATR) and F6-96.03\% (AML) and 97.66\% (ATR). Similar effects observed in the formulations F7 to F12 i.e. increase in \% CDR with increase in concentration super-disintegrants in formulations of F760.16\% (AML) and 48.36\% (ATR), F8-62.93\% (AML) and 51.63\% (ATR), F9-69.06\% (AML) and 61.23\% (ATR), F10-76.83\% (AML) and $64.6 \%$ (ATR), F11-88.83\% (AML) and $86.73 \%$ (ATR) and F12$87.16 \%$ (AML) and $84.63 \%$ (ATR). But the \%CDR of the formulation F1 to F6 containing Co-A AML-ATR is much higher than that of the formulation F7 to F12 containing crystalline ATR and AML counterpart, which is mainly, corresponds to the amorphous nature of both AML and ATR. Among twelve formulations F5, F6, F11 and F12 are satisfying the IP specification limits (fig. 14, 15, 16 and 17). Results from all above-mentioned pre-formulation, precompression, and post-compression parameters concluded that F5 and $\mathrm{F} 6$ are considered as best and optimized formulations among all.

\section{Stability study}

Optimized formulations F5 and F6 were subjected to stability studies at $25{ }^{\circ} \mathrm{C} \pm 2{ }^{\circ} \mathrm{C} / 60 \% \pm 5 \% \mathrm{RH}$ and $40{ }^{\circ} \mathrm{C} \pm 2{ }^{\circ} \mathrm{C} / 75 \% \pm 5 \%$ RH to assess their accelerated stability as per ICH guidelines Q1C for a period of $3 \mathrm{mo}$. At the end of 30, 60, and $90 \mathrm{~d}$ samples were evaluated.

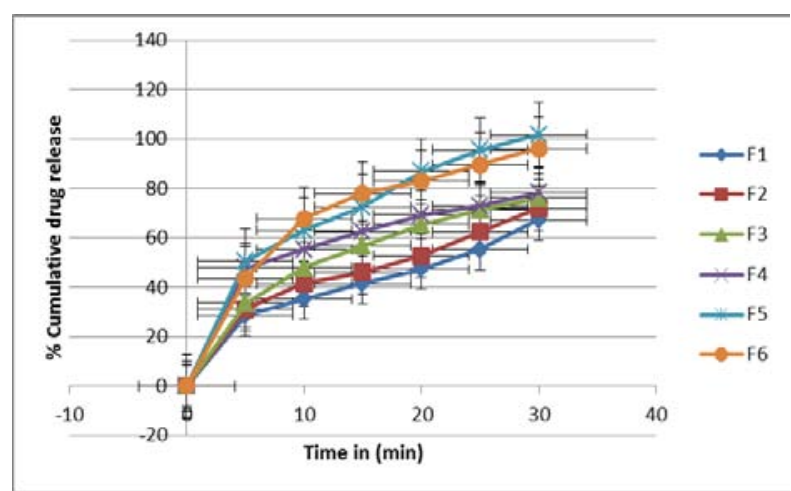

Fig. 13: In vitro dissolution profile of AML formulation from $F 1$ to F6 in scatter chart

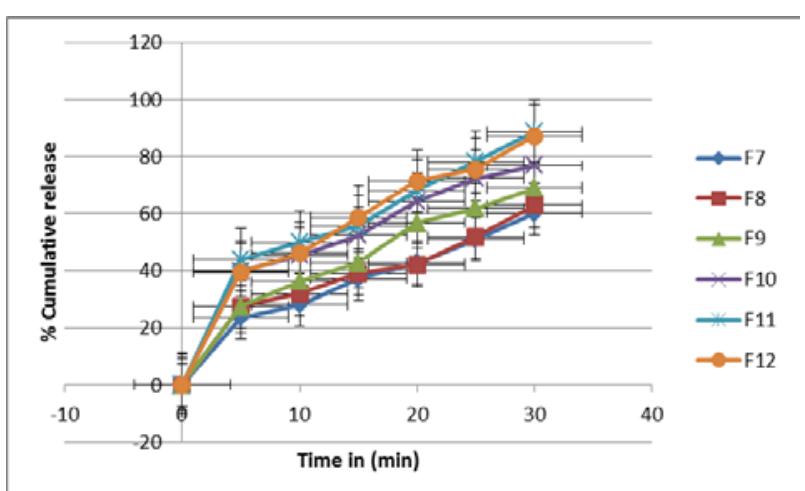

Fig. 14: In vitro dissolution profile of AML formulation from F7 to F12 in scatter chart

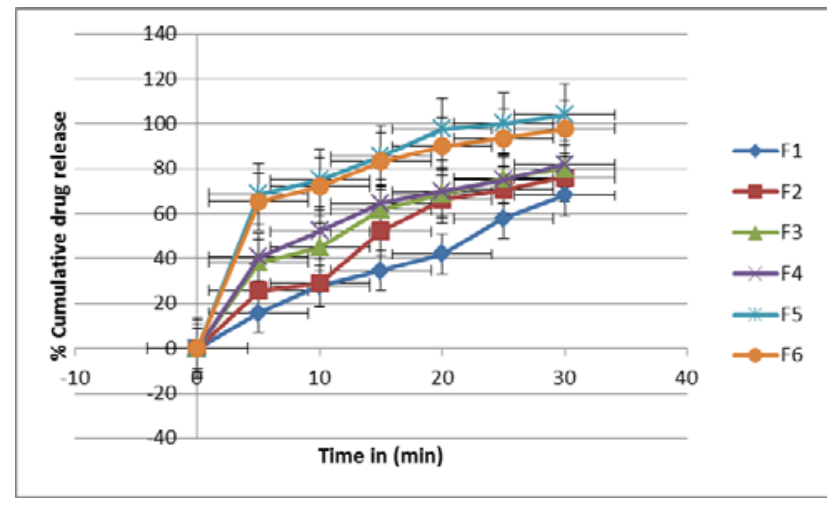

Fig. 15: In vitro dissolution profile of ATR formulation from F1 to F6 in scatter chart

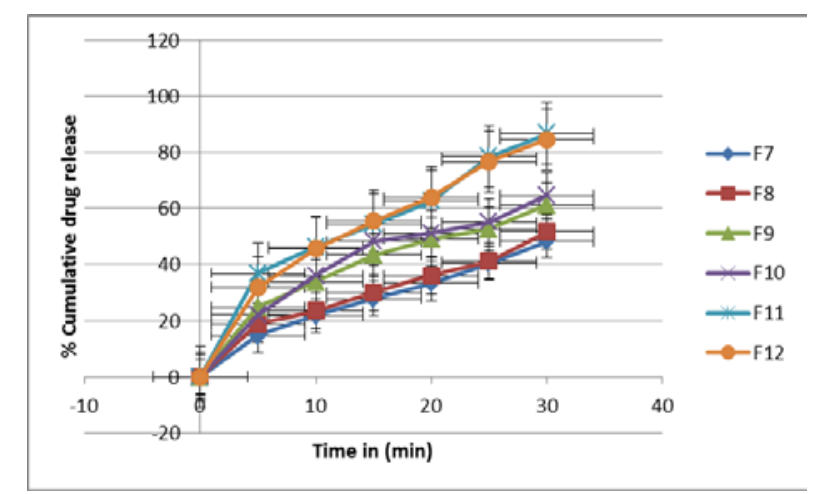

Fig. 16: In vitro dissolution profile of ATR formulation from F7 to F12 in scatter chart

There were no major changes in the evaluated parameters like hardness, drug content, and in vitro dissolution pattern.

1. Stability study of optimized formulation $\mathrm{F} 5$ at $25^{\circ} \mathrm{C} / 60 \% \mathrm{RH}$ :

Table 8: Evaluation of hardness and content uniformity of formulation F5

\begin{tabular}{lllll}
\hline Tests & & Initial & 1 $^{\text {st }}$ month & 2 $^{\text {nd }}$ months \\
\hline Hardness $^{*}$ in $\left(\mathrm{kg} / \mathrm{cm}^{2}\right)$ & & $6.82 \pm 0.2$ & $6.82 \pm 0.6$ & $6.8 \pm 0.8$ \\
Drug content* & AML & $102.24 \pm 0.7$ & $101.05 \pm 0.6$ & $6.8 \pm 0.3$ \\
in (\%) & ATR & $104.5 \pm 0.6$ & $103.64 \pm 0.3$ & $98.71 \pm 0.5$ \\
\hline
\end{tabular}

$*_{\text {mean } \pm S D}(\mathrm{n}=3)$ 
Table 9: In vitro dissolution profile of AML of formulation F5

\begin{tabular}{llll}
\hline & \multicolumn{3}{c}{ Dissolution studies } \\
\hline \multicolumn{2}{l}{ Time in (min) } & \% Cumulative drug release* in (\%) & $\mathbf{2}^{\text {nd }}$ months \\
\hline 0 & Initial & $\mathbf{1}^{\text {st }}$ month & 0.0 \\
5 & 0.0 & 0.0 & $47.36 \pm 0.5789$ \\
10 & $50.63 \pm 0.6027$ & $48.56 \pm 0.5876$ & $59.57 \pm 0.6742$ \\
15 & $63.03 \pm 0.1527$ & $61.02 \pm 0.9823$ & $69.45 \pm 0.6872$ \\
20 & $72.4 \pm 0.45825$ & $70.54 \pm 0.6428$ & $82.75 \pm 0.6428$ \\
25 & $86.9 \pm 0.81853$ & $85.98 \pm 0.578$ & $93.87 \pm 0.78521$ \\
30 & $95.56 \pm 0.3511$ & $94.67 \pm 0.6248$ & $98.58 \pm 0.5741$ \\
\hline
\end{tabular}

${ }^{*}$ mean \pm SD $(n=3)$

Table 10: In vitro dissolution profile of ATR of formulation F5

\begin{tabular}{llll}
\hline & \multicolumn{3}{c}{ Dissolution studies } \\
\hline Time in (min) & \% Cumulative drug release* in (\%) & 2 $^{\text {nd }}$ months \\
\hline 0 & Initial & $\mathbf{1}^{\text {st }}$ month & 0.0 \\
5 & 0.0 & 0.0 & $66.54 \pm 0.8726$ \\
10 & $68.66 \pm 0.585$ & $67.54 \pm 0.3256$ & $70.64 \pm 0.5426$ \\
15 & $74.93 \pm 0.2081$ & $72.64 \pm 0.5873$ & $81.02 \pm 0.6874$ \\
20 & $85.56 \pm 0.550$ & $82.45 \pm 0.8246$ & $92.97 \pm 0.4875$ \\
25 & $97.53 \pm 0.6110$ & $95.83 \pm 0.5721$ & $98.56 \pm 0.816$ \\
30 & $100.13 \pm 0.152$ & $99.87 \pm 0.8254$ & $100.96 \pm 0.2546$ \\
\hline
\end{tabular}

${ }^{*}$ mean $\pm \mathrm{SD}(\mathrm{n}=3)$

2. Stability study of optimized formulation $\mathrm{F} 6$ at $25^{\circ} \mathrm{C} / 60 \% \mathrm{RH}$ :

Table 11: Evaluation of hardness and content uniformity of formulation F6

\begin{tabular}{lllll}
\hline Tests & & Initial & $\mathbf{1}^{\text {st }}$ month & 2 $^{\text {nd }}$ months \\
\hline Hardness* in $\left(\mathrm{kg} / \mathrm{cm}^{2}\right)$ & & $5.53 \pm 0.1$ & $5.52 \pm 0.5$ & $5.48 \pm 0.6$ \\
Drug content* in $(\%)$ & AML & $99.00 \pm 0.2$ & $98.17 \pm 0.2$ & $97.21 \pm 0.6$ \\
& ATR & $102.2 \pm 0.4$ & $101.06 \pm 0.9$ & $96.26 \pm 0.3$ \\
\hline
\end{tabular}

*mean \pm SD $(n=3)$

Table 12: In vitro dissolution profile of AML of formulation F6

\begin{tabular}{llll}
\hline \multicolumn{4}{c}{ Dissolution studies } \\
\hline \multicolumn{2}{l}{ Time in (min) } & \% Cumulative drug release* in (\%) & \\
\hline 0 & Initial & $\mathbf{1}^{\text {st }}$ month & 2 $^{\text {nd }}$ months \\
5 & 0.0 & 0.0 & 0.0 \\
10 & $43.7 \pm 0.6244$ & $43.12 \pm 0.5463$ & $40.57 \pm 0.2651$ \\
15 & $67.76 \pm 0.7098$ & $66.7 \pm 0.3542$ & $64.89 \pm 0.2671$ \\
20 & $78.03 \pm 0.1523$ & $76.36 \pm 0.2354$ & $75.12 \pm 0.3215$ \\
25 & $82.93 \pm 0.7767$ & $80.58 \pm 0.1686$ & $78.35 \pm 0.8751$ \\
30 & $89.63 \pm 0.7098$ & $87.98 \pm 0.1257$ & $86.12 \pm 0.8756$ \\
\hline
\end{tabular}

*mean \pm SD $(n=3)$

Table 13: In vitro dissolution profile of ATR of formulation F6

\begin{tabular}{llll}
\hline & \multicolumn{3}{c}{ Dissolution studies } \\
\hline \multicolumn{2}{c}{ Time in (min) } & \% Cumulative drug release* in (\%) & \\
\hline 0 & Initial & 1 $^{\text {st }}$ month & 2 \\
5 & 0.0 & 0.0 & 0.0 \\
10 & $65.23 \pm 0.5859$ & $62.26 \pm 0.8742$ & $60.85 \pm 0.1283$ \\
15 & $71.96 \pm 0.1527$ & $70.65 \pm 0.1274$ & $68.93 \pm 0.364$ \\
20 & $83.16 \pm 0.3785$ & $81.92 \pm 0.4785$ & $79.34 \pm 0.521$ \\
25 & $89.8 \pm 0.7211$ & $88.56 \pm 0.8753$ & $86.24 \pm 0.2682$ \\
30 & $93.53 \pm 0.5507$ & $91.98 \pm 0.1249$ & $90.23 \pm 0.1248$ \\
\end{tabular}

*mean \pm SD $(\mathrm{n}=3)$ 
3. Stability study of optimized formulation $\mathrm{F} 5$ at $40{ }^{\circ} \mathrm{C} / 75 \% \mathrm{RH}$ :

Table 14: Evaluation of hardness and content uniformity of formulation F5

\begin{tabular}{|c|c|c|c|c|c|}
\hline Tests & & Initial & $1^{\text {st }}$ month & $2^{\text {nd }}$ months & $3^{\text {rd }}$ months \\
\hline Hardness* in $\left(\mathrm{kg} / \mathrm{cm}^{2}\right)$ & & $6.82 \pm 0.2$ & $6.79 \pm 0.3$ & $6.60 \pm 0.2$ & $6.51 \pm 0.3$ \\
\hline Drug content* in $(\%)$ & AML & $102.24 \pm 0.7$ & $100.14 \pm 0.3$ & $98.16 \pm 0.5$ & $97.01 \pm 0.5$ \\
\hline & ATR & $104.5 \pm 0.6$ & $103.2 \pm 0.1$ & $102.03 \pm 0.4$ & $99.69 \pm 0.3$ \\
\hline
\end{tabular}

*mean \pm SD $(\mathrm{n}=3)$

Table 15: In vitro dissolution profile of AML of formulation F5

\begin{tabular}{|c|c|c|c|c|}
\hline \multicolumn{5}{|c|}{ Dissolution studies } \\
\hline \multirow[t]{2}{*}{ Time in (min) } & \multicolumn{4}{|c|}{ \% Cumulative drug release* in (\%) } \\
\hline & Initial & $1^{\text {st }}$ month & $2^{\text {nd }}$ months & $3^{\text {rd }}$ months \\
\hline 0 & 0.0 & 0.0 & 0.0 & 0.0 \\
\hline 5 & $50.63 \pm 0.6027$ & $46.21 \pm 0.5428$ & $46.12 \pm 0.7937$ & $45.98 \pm 0.8274$ \\
\hline 10 & $63.03 \pm 0.1527$ & $60.12 \pm 0.8326$ & $57.04 \pm 0.1272$ & $57.1 \pm 0.3462$ \\
\hline 15 & $72.4 \pm 0.45825$ & $69.81 \pm 0.1243$ & $68.03 \pm 0.1426$ & $66.83 \pm 0.1274$ \\
\hline 20 & $86.9 \pm 0.81853$ & $83.15 \pm 0.6378$ & $80.14 \pm 0.3417$ & $78.90 \pm 0.4783$ \\
\hline 25 & $95.56 \pm 0.3511$ & $93.01 \pm 0.8172$ & $92.12 \pm 0.1281$ & $88.63 \pm 0.1932$ \\
\hline 30 & $101.7 \pm 0.6244$ & $98.91 \pm 0.3762$ & $97.03 \pm 0.8264$ & $96.03 \pm 0.2631$ \\
\hline
\end{tabular}

${ }^{*}$ mean $\pm \mathrm{SD}(\mathrm{n}=3)$

Table 16: In vitro dissolution profile of ATR of formulation F5

\begin{tabular}{|c|c|c|c|c|}
\hline \multicolumn{5}{|c|}{ Dissolution studies } \\
\hline \multirow{2}{*}{ Time in (min) } & \multicolumn{4}{|c|}{ \% Cumulative drug release* in (\%) } \\
\hline & Initial & $1^{\text {st }}$ month & $2^{\text {nd }}$ months & $3^{\text {rd }}$ months \\
\hline 0 & 0.0 & 0.0 & 0.0 & 0.0 \\
\hline 5 & $68.66 \pm 0.585$ & $66.83 \pm 0.7832$ & $64.96 \pm 0.763$ & $63.92 \pm 0.4875$ \\
\hline 10 & $74.93 \pm 0.2081$ & $71.93 \pm 0.1211$ & $68.01 \pm 0.7314$ & $67.98 \pm 0.1765$ \\
\hline 15 & $85.56 \pm 0.550$ & $80.83 \pm 0.762$ & $80.83 \pm 0.2174$ & $78.04 \pm 0.731$ \\
\hline 20 & $97.53 \pm 0.6110$ & $93.35 \pm 0.1823$ & $91.74 \pm 0.4231$ & $89.98 \pm 0.875$ \\
\hline 25 & $100.13 \pm 0.152$ & $98.12 \pm 0.4381$ & $97.43 \pm 0.1238$ & $96.79 \pm 0.6751$ \\
\hline 30 & $103.9 \pm 0.6557$ & $100.28 \pm 0.8234$ & $99.01 \pm 0.7124$ & $97.94 \pm 0.1261$ \\
\hline
\end{tabular}

*mean \pm SD $(n=3)$

4. Stability study of optimized formulation $\mathrm{F} 6$ at $40{ }^{\circ} \mathrm{C} / 75 \% \mathrm{RH}$

Table 17: Evaluation of hardness and content uniformity of formulation F6

\begin{tabular}{|c|c|c|c|c|c|}
\hline Tests & & Initial & $1^{\text {st }}$ month & $2^{\text {nd }}$ months & $3^{\text {rd }}$ months \\
\hline Hardness* in $\left(\mathrm{kg} / \mathrm{cm}^{2}\right)$ & & $5.53 \pm 0.2$ & $5.01 \pm 0.4$ & $5.3 \pm 0.9$ & $5.27 \pm 0.7$ \\
\hline Drug content* in (\%) & AML & $99.00 \pm 0.3$ & $97.42 \pm 0.8$ & $96.77 \pm 0.7$ & $98.26 \pm 0.2$ \\
\hline & ATR & $102.2 \pm 0.5$ & $102.06 \pm 0.9$ & $101.98 \pm 0.8$ & $101.76 \pm 0.3$ \\
\hline
\end{tabular}

*mean \pm SD $(n=3)$

Table 18: In vitro dissolution profile of AML of formulation F6

\begin{tabular}{|c|c|c|c|c|}
\hline \multicolumn{5}{|c|}{ Dissolution studies } \\
\hline \multirow[t]{2}{*}{ Time in (min) } & \multicolumn{4}{|c|}{$\%$ Cumulative drug release* in (\%) } \\
\hline & Initial & $1^{\text {st }}$ month & $2^{\text {nd }}$ months & $3^{\text {rd }}$ months \\
\hline 0 & 0.0 & 0.0 & 0.0 & 0.0 \\
\hline 5 & $43.7 \pm 0.6244$ & $42.98 \pm 0.6534$ & $39.54 \pm 0.2633$ & $37.01 \pm 0.9731$ \\
\hline 10 & $67.76 \pm 0.7098$ & $68.98 \pm 0.1202$ & $59.83 \pm 0.431$ & $62.81 \pm 0.142$ \\
\hline 15 & $78.03 \pm 0.1523$ & $75.98 \pm 0.1521$ & $74.09 \pm 0.736$ & $73.91 \pm 0.4739$ \\
\hline 20 & $82.93 \pm 0.7767$ & $79.56 \pm 0.6352$ & $77.56 \pm 0.2461$ & $75.81 \pm 0.6537$ \\
\hline 25 & $89.63 \pm 0.7098$ & $86.26 \pm 0.7354$ & $85.15 \pm 0.5273$ & $83.98 \pm 0.7235$ \\
\hline 30 & $96.03 \pm 0.1523$ & $94.96 \pm 0.2671$ & $93.97 \pm 0.4654$ & $90.03 \pm 0.1162$ \\
\hline
\end{tabular}

\footnotetext{
*mean \pm SD $(\mathrm{n}=3)$
} 
Table 19: In vitro dissolution profile of ATR of formulation F6

\begin{tabular}{llll}
\hline & \multicolumn{3}{c}{ Dissolution studies } \\
\hline Time in (min) & \% Cumulative drug release* $\mathbf{~ i n ~ ( \% ) ~}$ & $\mathbf{2}^{\text {nd }}$ months \\
\hline 0 & Initial & $\mathbf{1}^{\text {st }}$ month & 0.0 \\
5 & 0.0 & 0.0 & $59.74 \pm 0.6373$ \\
10 & $65.23 \pm 0.5859$ & $61.75 \pm 0.7361$ & $67.35 \pm 0.2672$ \\
15 & $71.96 \pm 0.1527$ & $69.98 \pm 0.638$ & $78.93 \pm 0.3234$ \\
20 & $83.16 \pm 0.3785$ & $80.73 \pm 0.7823$ & $87.02 \pm 0.3671$ \\
25 & $89.8 \pm 0.7211$ & $86.76 \pm 0.2012$ & $89.73 \pm 0.5361$ \\
30 & $93.53 \pm 0.5507$ & $90.83 \pm 0.2736$ & $77.35 \pm 0.7351$ \\
\hline
\end{tabular}

${ }^{*}$ mean \pm SD $(\mathrm{n}=3)$

\section{CONCLUSION}

Both AML and ATR (BCS class II drugs) were successfully converted to amorphous form by the use of rotary flash evaporator apparatus. The amorphous form was confirmed by detection of halo pattern in XRPD studies. The absence of intermolecular interaction between both the APIs, APIs with formulation blend, converted the coamorphous form of AML-ATR, and co-A AML-ATR with formulation blend. Almost one fold increase in the solubility of both amorphous AML and ATR was found as compared to their respective crystalline counterparts. The study demonstrated successful utilization of both the physical and co-amorphous forms in tablet formulations by direct compression technique using SSG and CP. The study also demonstrated a significant increase in dissolution rate not only with respect to increasing in the concentration of both SSG and CP but also dependent on nature (i.e., crystalline or amorphous form) of the APIs utilized in the formulation of tablets. Optimized formulations were found no significant changes and extremely stable in tested stability conditions for three months.

\section{ACKNOWLEDGMENT}

The authors would like to acknowledge Dr. Reddy's Laboratories LTD, Hyderabad, Telangana for providing APIs. Dr. K. Lakshman, HOD, department of Pharmacognosy, PES College of Pharmacy, Bengaluru for providing rotary flash evaporator instrumentation support, Dr. Nagaraj, HOD and Rachana Achary, post graduate, department of Pharmaceutical Analysis, PES College of Pharmacy, Bengaluru for proving FTIR instrumentation support, Prof. T. N. Guru Row, Mr. Praveen B. Mangutti (Research scholar), and Mr. Amar (Research scholar), Indian Institute of Science, Bengaluru, for providing XRPD instrumentation support.

\section{CONFLICTS OF INTERESTS}

Declared none

\section{REFERENCES}

1. Kaplan N, Bakris G, Forman J. Antihypertensive drugs and lipids. Available from: http://www.uptodate.com/contents/ antihypertensive-drugs-and-lipids. [Last accessed on 10 Apr 2016].

2. Alani L, Khan S, Macneil T, Muhammad N. Patent W02003011283A1-Pharmaceutical Compositions of Amlodipine and Atorvastatin; 2003. Available from: https://www.google.com/patents/W02003011283A1?cl=enan $\mathrm{ddq}=\mathrm{WO}+2003011283 \mathrm{~A} 1 *$ andhl=enandsa=Xandved=0ahUKEw j9ituYpODLAhWN1I4KHRlbBS4Q6AEIHTAA. [Last accessed on 10 Apr 2016].

3. Mason R. Patent W02000064443A1-Synergistic Effects of amlodipine and atorvastatin; 2000. Available from: http://www.google.com/patents/W02000064443A1?cl=en11. [Last accessed on 10 Apr 2016].

4. Buch J. Patent US6455574-Therapeutic Combination; 2000. Available from: https://www.google.com/patents/US6455574. [Last accessed on 10 Apr 2016].

5. Straub J, Bernstein H, Chickering III D, Khattak S, Randall G. Patent US6395300-Porous drug matrices and methods of manufacture thereof; 2002. Available from: https://www. google.com/patents/US6395300. [Last accessed on $10 \mathrm{Apr}$ 2016].
6. Jang D, Jeong E, Lee H, Kim B, Lim S, Kim C. Improvement of bioavailability and photostability of amlodipine using redispersible dry emulsion. Eur J Pharm Sci 2006;28:405-11.

7. Zhang H, Wang J, Zhang Z, Le Y, Shen Z, Chen J. Micronization of atorvastatin calcium by an antisolvent precipitation process. Int J Pharm 2009;374:106-13.

8. Talluri M, Kurian AB, Adahalli SB. Formulation and evaluation of self-emulsifying drug delivery system of an anti-diabetic drug. Int J Pharm Res Sci 2015;4:150-62.

9. Savjani K, Gajjar A, Savjani J. Drug solubility: importance and enhancement techniques. ISRN Pharm 2012:110. Doi:10.5402/2012/195727.

10. Alleso M, Chieng N, Rehder S, Rantanen J, Rades T, Aaltonen J. Enhanced dissolution rate and synchronized release of drugs in binary systems through formulation: Amorphous naproxencimetidine mixtures prepared by mechanical activation. J Controlled Release 2009;136:45-53.

11. Dengale S, Ranjan O, Hussen S, Krishna B, Musmade P, Gautham Shenoy G, et al. Preparation and characterization of Coamorphous ritonavir-indomethacin systems by solvent evaporation technique: improved dissolution behavior and physical stability without evidence of intermolecular interactions. Eur J Pharm Sci 2014;62:57-64.

12. Lobmann K, Strachan C, Grohganz H, Rades T, Korhonen O, Laitinen R. Co-amorphous simvastatin and glipizide combinations show improved physical stability without evidence of intermolecular interactions. Eur J Pharm Biopharm 2012;81:159-69.

13. Shayanfar A, Ghavimi H, Hamishekar H, Jouyban A. Co amorphous atorvastatin calcium to improve its physicochemical and pharmacokinetic properties. J Pharm Pharm Sci 2013;16:577-87.

14. Gao Y, Liao J, Qi X, Zhang J. Co amorphous repaglinidesaccharin with enhanced dissolution. Int J Pharm 2013;450:290-5.

15. Biswal S, Sahoo J, Murthy PN. Physicochemical properties of solid dispersions of gliclazide in polyvinylpyrrolidone K90. AAPS PharmSciTech 2009;10:9212-7.

16. Chieng N, Aaltonen J, Saville D, Rades T. Physical characterization and stability of amorphous indomethacin and ranitidine hydrochloride binary systems prepared by mechanical activation. Eur J Pharm Biopharm 2009;71:47-54.

17. Safarz KN. Handbook of Pharmaceutical Manufacturing Formulation; 2004. p. 426-7.

18. Banker G, Rhodes CT. Modern pharmaceutics. New York: Marcel Dekker, Inc; 2000. Available from: http://www. uspnf.com/ uspnf/pub/index?usp=38andnf=33ands=2andofficialOn=Decem ber\%201,\%202015. [Last accessed on 10 Apr 2016].

19. Reddy T, Banda S, Srinivas G. Design and development of fast dissolving tablet of amlodipine besylate and atorvastatin calcium. Int J Pharm Sci Rev Res 2013;23:290-4.

20. Banker G, Rhodes CT. Modern pharmaceutics. New York: Marcel Dekker, Inc; 2000.

21. The United States Pharmacopoeia-25\National Formulary-20 United States Pharmacopoeial Convention Inc. Canada; 2002. p. 1191-2.

22. British Pharmacopeia. Published on the recommendation of medicine commission. Sweetman SC. $33^{\text {rd }}$ edition. The Complete Drug Reference. 1993. p. 442-3, 874-6. 
23. Indian Pharmacopoeia. Vol. II. The government of India Ministry of the Health and Family Welfare, Published by the Controller of Publication, Delhi; 2007. p. 807-49.

24. Ahuja S, Scypinski S. Handbook of modern pharmaceutical analysis, London: Academic Press; 2012. p. 208.

25. http://www.ich.org/fileadmin/Public_Web_Site/ICH_Products /Guidelines/Quality/Q1A_R2/Step4/Q1A_R2_Guideline.pdf. [Last accessed on 10 Aug 1015].

\section{How to cite this article}

- Sachin Basavaraj Adahalli, Manjula Talluri. Formulation and evaluation of tablet prepared by the coamorphous system containing the anti-hypertensive and anti-hyperlipidemic drug. Int J Pharm Pharm Sci 2016;8(9):182-193. 